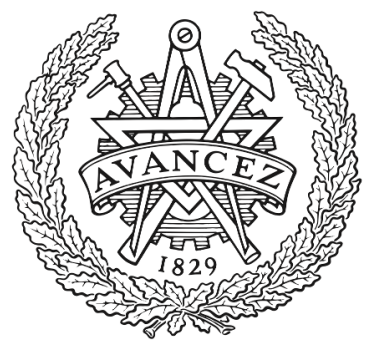

CHALMERS

UNIVERSITY OF TECHNOLOGY

\title{
Anchorage capacity of naturally corroded reinforcement in an existing bridge
}

Downloaded from: https://research.chalmers.se, 2023-04-25 23:18 UTC

Citation for the original published paper (version of record):

Berg, F., Johansson, D., Lundgren, K. et al (2012). Anchorage capacity of naturally corroded reinforcement in an existing bridge. Proceedings of the Sixth International Conference on Bridge Maintenance, Safety and Management, IABMAS 2012, Stresa, Lake Maggiore, 8-12 July 2012: 2800-2807. http://dx.doi.org/10.1201/b12352-428

N.B. When citing this work, cite the original published paper. 


\title{
Anchorage capacity of naturally corroded reinforcement in an existing bridge
}

\author{
F. Berg \& D. Johansson \\ Chalmers University of Technology, Gothenburg, Sweden
}

K. Zandi Hanjari

Swedish Cement and Concrete Research Institute (CBI), Borås, Sweden

K. Lundgren \& M. Plos

Chalmers University of Technology, Gothenburg, Sweden

ABSTRACT: Corrosion of reinforcement is one of the most common causes of deterioration in reinforced concrete bridges. Anchorage, prior to shear and bending moment resistance, is the main uncertainties in the evaluation of the structural behavior of corroded reinforced concrete bridges. Thus, to assess the remaining load-bearing capacity of deteriorated existing bridges, models to estimate the remaining bond and anchorage capacity are needed. Most of our knowledge on the structural behavior of corroded reinforced concrete structures is based on experimental investigations of artificially corroded concrete specimens. In this study, the anchorage capacity of naturally corroded steel reinforcement was investigated experimentally. The test specimens were taken from edge beams of a bridge, Stallbackabron, in Sweden. Since the dimensions and the amount of reinforcement were given on beforehand, it was only the test set-up which could be chosen freely. A test set-up consisting of a four point bending test indirectly supported with suspension hanger was considered to be the best alternative with the least disturbance and influence of the natural damages. Detailed design was done by using a non-linear finite element method. It was seen that the edge beams needed to be strengthened with transverse reiforcement, else they would have failed in a local failure at the suspension hole or in shear. The technique adopted for the strengthening was an internal mounting of steel reinforcement using epoxy as adhesive. The bond and anchorage behavior was examined in tests through measurements of applied load, free-end slip and mid-span deflection. A first test showed that additional measures were needed to ensure anchorage of the strengthening bars. In subsequent tests, they were therefore anchored at the top of the beam with hexagonal nuts and flat steel plates. In two following tests, the beams failed in a splitting induced pull-out failure, i.e. anchorage failure was achieved as wanted.

\section{INTRODUCTION}

\subsection{Background}

Corrosion of reinforcement is one of the most common causes of deterioration in reinforced concrete bridges. Anchorage, prior to shear and bending moment resistance, is the main uncertainties in the evaluation of the structural behavior of corroded reinforced concrete bridges. The bond behavior, i.e. the interaction between the steel reinforcement and the surrounding concrete, is decisive for both the load bearing capacity and the ductility in the ultimate state, as well for the stiffness distribution and the crack pattern in the service state. Thus, to assess the remaining load-bearing capacity of deteriorated existing bridges, models to estimate the remaining bond and anchorage capacity are needed.

Existing analytical and numerical models of bond of corroded reinforcement have been developed based on experimental investigations of artificially corroded specimens. However, there are reasons to believe that the deterioration caused by natural corrosion does not have the same effects on the structural behavior as the deterioration caused by artificial corrosion. Experimental evidences found in the literature show that common methods of accelerated induced corrosion, i.e. admixed chloride, impressed current and wet/drying techniques, may change the morphology of the corrosion products to different extent. Probably, the most influencing factor is the corrosion rate achieved by each method. Saifullah \& Clark (1994) carried out pull-out tests on specimens subjected to impressed current of different densities from 40 to $4000 \mu \mathrm{A} / \mathrm{cm}^{2}$, corresponding to approximately 20 to 200 times faster than naturally induced corrosion. Spurious bond deterioration was found for specimens subjected to impressed current higher than $250 \mu \mathrm{A} / \mathrm{cm}^{2}$. Another study by Austin et al. (2004) shows that the electrochemistry in naturally 
induced corrosion differs from accelerated corrosion. Dramatic reduction of the corrosion time from years to days is a rather strong justification for using accelerated induced corrosion in lab tests. However, a great care should be taken to interpret the results and extrapolate them to field conditions. Tests on naturally corroded concrete members are essential to investigate the reliability and representativeness in field conditions of the existing models, which are based on investigations of artificially corroded concrete members.

In this study, the anchorage capacity of naturally corroded steel reinforcement was investigated experimentally. The test specimens were taken from edge beams of a bridge, Stallbackabron, in Sweden. Since the dimensions and the amount of reinforcement were given on beforehand, it was only the test set-up which could be chosen freely. The test set-up was carefully chosen and designed by using non-linear finite element analysis of the tests in advance. The bond and anchorage behavior was examined through measurements of applied load, free-end slip and mid-span deflection.

\section{TEST SPECIMENS}

A rehabilitation of the bridge Stallbackabron located outside Trollhättan in Sweden started in August 2010 and is planned to be finished in August 2012. The rehabilitation consists of replacing the outermost slabs and the edge beams. The edge beams show different extent of corrosion induced damage, from no sign of corrosion to extensive cover cracking resulting in spalling of concrete cover. They were therefore considered to be very promising to be used in this research: since they are naturally corroded and showed different damage extents. The geometry of the edge beams was also suitable for bending tests, which makes it possible to evaluate the anchorage behavior at a structural level.

The edge beams were reinforced, both longitudinally and transversally, with deformed bars, i.e. ribbed bars. It is important to note that structures exposed to aggressive environment are susceptible to different types of deterioration, e.g. corrosion, frost, sulphate attack, etc. In Stallbackabron, although, corrosion has been the main cause of deterioration. The bridge also shows signs of frost deterioration; however, this has not been studied in this research.

Stallbackabron was built in 1981, and is thus only 30 years old. The severity of the deterioration has been enhanced by poor design of the bridge. The outermost slabs were too slender, and lack of transverse reinforcement in the slab forced the edge beams to work as a load distributer, carrying more load than they were designed for. Loaded structures always crack; the edge beams are no exception. The cracks enhance the chloride penetration of de-icing salts and the open cracks store up free water that in- crease the risk of severe frost damages. Transverse cracks in the joints of the slab accelerated the chloride penetration.

In Figure 1, the geometry of the edge beams is shown. They were $350 \mathrm{~mm} * 400 \mathrm{~mm}$ in crosssection, with a small inclination of the upper surface. The longitudinal reinforcement consisted of four bars $016 \mathrm{Ks} 60$ bundled in pairs in the upper part, and two bars $\varnothing 16 \mathrm{Ks} 60$ in the bottom. The transverse reinforcement consisted of $\varnothing 10 \mathrm{~s} 300 \mathrm{Ks} 40$.

The actual specimens diverged in many aspects from the drawings, due to altering accuracy and precision in workmanship during erection of the bridge. The specimens showed varying amount and position of the longitudinal reinforcement, together with shifting spacing distance between the transverse reinforcement, i.e. the stirrups. The concrete cover also varied.

The longitudinal reinforcement bars closest to the upper inclined surface of the edge beams were more damaged than the other longitudinal bars. Therefore, they were considered to be more interesting in the investigation of bond and anchorage behavior. The higher extent of corrosion induced damage is reasonable since the upper bars during its service life time were most exposed to de-icing salts.

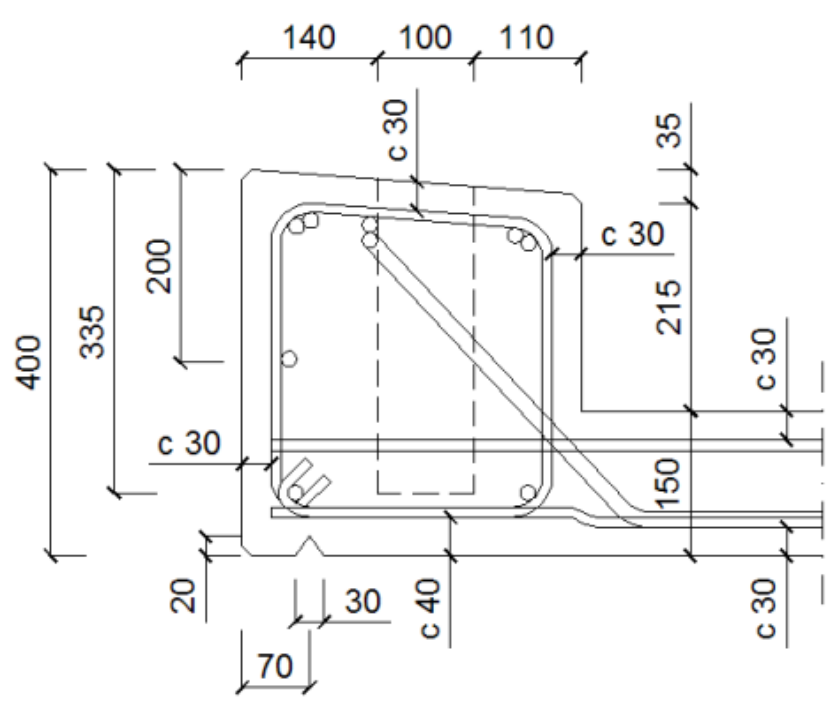

Figure 1. Detail of edge beam

\section{DESIGN OF TEST SET-UP}

Different test set-ups were examined and evaluated. The most promising test configuration was then designed in detail by using non-linear finite element method.

\subsection{Choice of test set-up}

The test configuration had to be thoroughly designed to secure anchorage failure for beams with various corrosion damage levels in one common test set-up. To capture anchorage failure without influencing 
and disturbing the natural damages of the edge beams was of great interest. In other words, it was of great importance to avoid any damage to the beams during preparation.

Four different test configurations were considered in the choice of a test set-up: a pull-out test; a beamend test; a directly supported four point bending test; and an indirectly supported four point bending test. They are all illustrated in Figure 2.

The pull-out test was excluded since it would have been very difficult to grab the bundled bars. The eccentric position of the bars would also have complicated the test. Furthermore, preparation of specimens for pull-out test would also have disturbed the region around the bars and influenced the bond properties. The pull-out test would otherwise have been favorable as it gives a well defined anchorage length.

The beam-end test also has a well defined anchorage length and represents the structural behavior in a better way than the pull-out test. However, the beam-end test, like the pull-out test, includes the difficulty of gripping the reinforcement bars. It also has a large impact on the natural damages which should be avoided; thus, this test set-up was discarded.

The directly supported four point bending test has the advantage of not including gripping of the bundled bars. Furthermore, it will likely result in better defined anchorage length in comparison to the indirect support; because inclined shear cracks often propagate to the direct support. One concern with this test set-up is that the support pressure will influence the anchorage behavior to a large extent. With external transverse pressure acting in the anchorage region, i.e. along the transmission length, both bond stiffness and strength increase, see e.g. Lundgren \& Magnusson (2001) or Zandi Hanjari (2010). As the major influence of corrosion on bond is that the confinement is reduced due to cracking and eventually spalling, it would be inappropriate to use a test setup which compensates for this; as support pressure is not always present in real anchorage situations, e.g. in splices or cut-off regions. Finally, for severely damaged members with cover spalling in the end regions, a test configuration with direct supports would not be possible without repairing the specimens to get a flat surface for the supports. As the intention was to study the effect of spalled cover, this was considered to be unacceptable. Therefore, the test set-up with a directly supported four point bending test was left out.
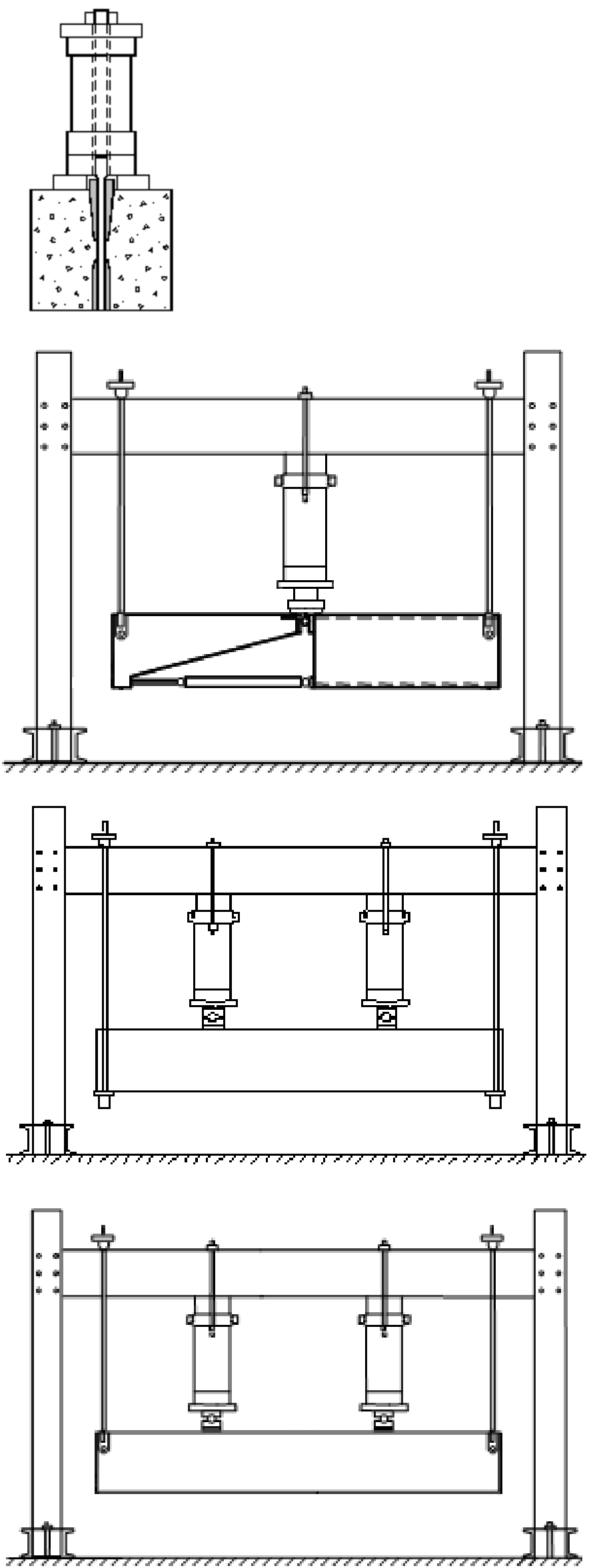

Figure 2. Examples of test set-ups: a pull-out test; a beam-end test; a directly supported four point bending test; and an indirectly supported four point bending test. Figures from Magnusson (2000). 
The four point bending test, indirectly supported with suspension hangers, does not include problems with gripping the bundled bars, and the part with spalled cover can be left as it is. One disadvantage with the test-set-up, though, is that it required strengthening of the available specimens, for them to be able to withstand the hanging support reactions. With a carefully designed strengthening, this test set-up was thus considered to be the best choice with least disturbance and influence on the natural damages of the edge beams while capturing the structural behavior.

\subsection{Finite Element Method-FEM}

The four point bending test, indirectly supported with suspension hangers, was designed in detail so that an anchorage failure took place. This was done in a parametric study by simulating the test set-up using non-linear finite element method, prior to actual testing. The finite element program DIANA, version 9.4.3, together with the pre- and postprocessor $\mathrm{FX}+$, version 3.0.0, was used for the analyses. For more details of the analyses, see Berg \& Johansson (2011).

Several parameters were investigated: the location of the suspension hole, the position of the concentrated loads and the influences of notches. With respect to the shear capacity, it was considered to be important to place the load so that the load path crosses at least one stirrup. Data of the material properties corresponding to the ribbed hot-rolled reinforcement bars, Ks40 and Ks60, were received from old tests at Chalmers University of Technology, from the time when Stallbackabron was built. The concrete strength was estimated from what was given on drawings.

\subsection{Three-dimensional simulations}

An example of a finite element model in three dimensions is illustrated in Figure 3. Due to symmetry, only a half-member was analyzed. Several simplifications were made, such as not including the deterioration of corrosion and frost. Deviations of the position and the varying amount of the longitudinal and transverse reinforcement were also not accounted for. Note that these simplifications were only used in the preliminary analyses used to design the test set-up. In later work, analyses of the tests will be done to better evaluate the results; then these simplifications will be reassessed and probably not used.

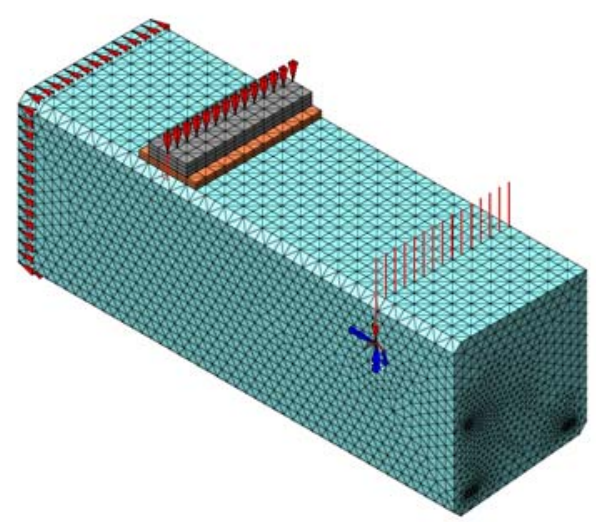

Figure 3. An example of a finite element model in three dimensions.

The longitudinal tensile reinforcement were modeled using solid elements. The compressive and transverse reinforcement were modeled as embedded in the concrete elements, i.e. assuming perfect bond between the reinforcement and the concrete.

The constitutive models for concrete were based on non-linear fracture mechanics using a smeared rotating crack model with Hordijk and Thorenfeldt models describing tensile and compressive behaviors, respectively, see DIANA (2009). The constitutive behavior of the reinforcing steel was modeled by an elastic, perfectly plastic material model. The elastic state was limited by the von Mises yield criterion, with associated flow and isotropic strain hardening.

Interaction between the longitudinal main reinforcement and the concrete was modeled with a bond model, developed and described in Lundgren (2005a). The bond model is a frictional model, including the splitting stresses of the bond action. Thus, the bond stress depends not only on the slip, but also on the radial deformation or the normal stress between the reinforcement bar and the surrounding concrete. The bond model was implemented as a user-supplied subroutine in DIANA. The programming was done in FORTRAN, and the complete code can be found in Lundgren (2001).

The numerical solution approach for the nonlinear calculations was based on a two-phase analysis. In the first phase, the self-weight was applied in one single step. The second phase represents the variable point loads, with user defined load steps. The monotonically increasing load was applied as displacements. A regular Newton-Raphson method, a non-linear solution technique, was used as iteration scheme in order to find equilibrium within each displacement increment. 


\subsection{Results}

In an extensive parametric study, shear failure or local failure of the suspension seemed to be critical independently of the test settings; therefore, it was concluded that the beams needed to be strengthened with transverse reinforcement. Internal mounting was considered to be the most promising option. In this method, vertical holes are drilled and reinforcing ribbed steel bars or cylindrical FRP rods are bonded using either epoxy adhesive or cement mortar.

The number of strengthening reinforcing steel bars, their location, dimension, and steel quality, was determined by running a number of analyses until there was no considerable risk of yielding of the strengthening reinforcing steel. With respect to the load-bearing capacity, it was considered to be essential to provide the beam with pairs of strengthening bars on both sides of the suspension hole. The location of the bars was not varied that much throughout the analyses; however, the effect of the steel quality and the dimension were investigated to a larger extent. The bars, used in the strengthening, were modeled as embedded.

The development of cracks in the shear span was crucial in the analyses; this since the inclined shear cracks had to cross the tensile reinforcement, close to the section of suspension, for the anchorage to become critical. Due to the inclined cracks in the shear span, the tensile stresses in the main reinforcement increased; at the same time the available anchorage length decreased. The first cracks were of flexural type and occurred between the two concentrated loads. With increased load, flexural cracks and inclined shear cracks developed in the shear span, where the flexural cracks formed close to the stirrups and the inclined shear cracks curved towards the concentrated loads. The anchorage became more stressed when the cracks propagated towards the support. At a critical stage, the transmission length was too short in order to transfer the tensile forces in the main reinforcement bars to the surrounding concrete; i.e. the beam failed due to insufficient anchorage of the tensile reinforcement.

The three-dimensional analysis showed no substantial, but still recognizable, residual load-bearing capacity. The free end slip were considerable $(0.1-$ $0.2 \mathrm{~mm}$ ) in the pre-peak stage; i.e. up to maximum load; subsequently, the free end slip increased while the load was constant

\section{EXPERIMENTS}

All tests were performed at the laboratory of Structural Engineering at Chalmers University of Technology. For more detailed information about test set-up etc., see Berg \& Johansson (2011).

\subsection{Material properties}

Tests of the cylindrical compressive strength $\left(f_{c, c y l}\right)$, according to the Swedish Standard SS-EN 12390-3, were conducted. The test specimens were drilled according to Swedish Standard SS -EN 12504-1. The drilled cores had a height of $108 \mathrm{~mm}$ and a diameter of $54 \mathrm{~mm}$. Considering the small diameter, the strength value was recalculated according to Swedish Standard SS -EN 1372 07. All these standards are given in Swedish Standards Institute (2002). The strength value given in Table 1, was determined as the mean value from series of five tests.

The compressive strength was also measured with a test hammer. The hammer was of type $\mathrm{N}$ with impact energy of 2,207 $\mathrm{Nm}$. The test was carried out on the short face of the beam. The compressive strength in Table 1 shows the mean value of ten tests.

Table 1. Compressive strength of concrete.

\begin{tabular}{lll}
\hline & $\begin{array}{l}f_{\text {cc,cyl }} \\
{[\mathrm{MPa}]}\end{array}$ & $\begin{array}{l}f_{\text {cc,hammer }} \\
{[\mathrm{MPa}]}\end{array}$ \\
\hline Concrete & 49.5 & 44.0 \\
\hline
\end{tabular}

\subsection{Experimental set-up}

As discussed in section 3.1, a four point bending test, indirectly supported with suspension hangers, was chosen as it was considered to have least disturbance and influence on the natural damages of the edge beams while capturing the structural behavior. The cut edge beams were positioned upside down so that the most corroded bars were loaded in tension. Turning the specimens upside down at testing also facilitated the loading, since the load worked on a flat surface instead of a surface with an inclination.

The load was applied by two symmetrically placed hydraulic jacks and was measured by load gauges, i.e. load cells, placed on top of each jack. Tests were conducted by displacement control. Displacement transducers measured the vertical displacements relative to the floor in mid span, in sections of the suspensions, and the loads. Displacement transducers, one per main bar, were placed on the short-face of the beam ends to measure the free end slip of the longitudinal reinforcement. The end slip was measured relative to a point on the short-face of the beam end, located about $80 \mathrm{~mm}$ above the uppermost main reinforcement bar. The displacement transducers were positioned by magnetic stands attached to a steel plate, anchored on the short face. All of the data were continuously stored in a data-log, $1 \mathrm{log} / \mathrm{s}$. In addition, the crack development was continuously registered. 


\subsection{First beam test}

The first test was performed on a specimen of medium damage level; thus some cracking due to corrosion was present but no cover spalling. The beam was strengthened with $4 ø 16$ B500B at each suspension hole, bonded to the concrete with epoxy. However, the test resulted in a local failure at the suspension hole, due to insufficient anchorage of the strengthening steel bars. The transmission length between the critical crack, initiating from the suspension hole and propagating to the adjacent concentrated load and to the free end, was too short, i.e. the chemical adhesion from the epoxy could not withstand the bond stresses. The required transmission length, i.e. the critical anchorage length, was hard to predict since few studies have been made dealing with the bond behavior and the corresponding anchorage capacity of steel reinforcement bars, assembled to concrete structures using epoxy adhesive. The maximum load was only about $170 \mathrm{kN}$. As the edge beam failed in an unwanted local failure at the suspension hole, no free end slip of the tensile reinforcement were measured.

\subsection{Second and third beam tests}

The experience gained from the first beam test led to a modification of the strengthening, shown in Figure 4. The strengthening bars from the first test were replaced by bars of prestressing steel (dywidags) with a diameter of $20 \mathrm{~mm}$. The high yield reinforcing steel bars, fully threaded, were anchored at the top of the beam with hexagonal nuts and flat steel plates. The mechanical docking of the bars, by means of threaded coupling, was considered to provide the additional anchorage needed. The bars were bonded to the concrete with epoxy, the same technique used in the first test. Epoxy was also applied in between the flat steel plate and the concrete beam in order to obtain even pressure.

The specimen used in the second test was almost undamaged; i.e. only small cracks due to corrosion were visible before the test. The specimen used in the third test had severe damages due to corrosion, with cover spalling. Photos of the test specimens before testing are shown in Figures 5 and 6.

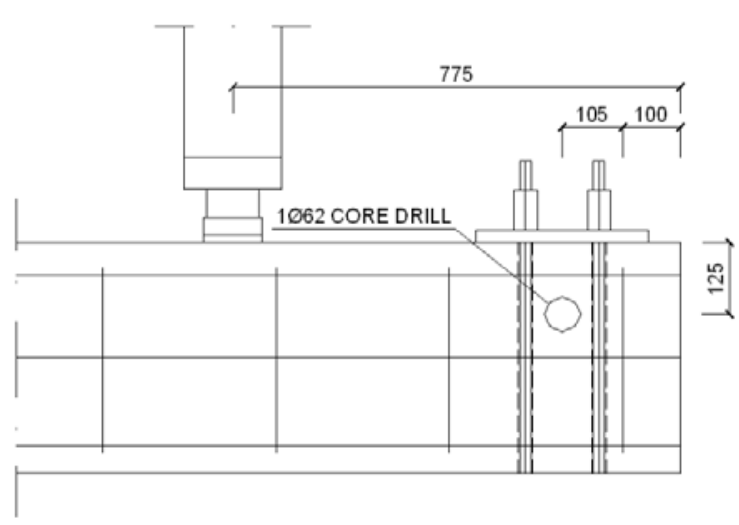

\section{ELEVATION}

Figure 4. Details of second test set-up with improved anchorage of the strengthening bars.

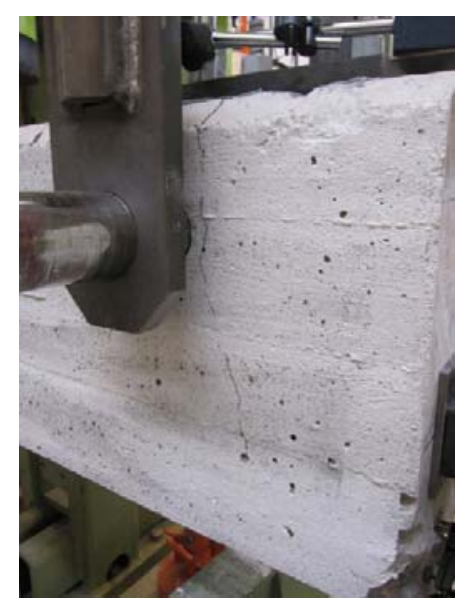

Figure 5. Photo taken before testing, at the end where failure later took place. Second test specimen, low corrosion

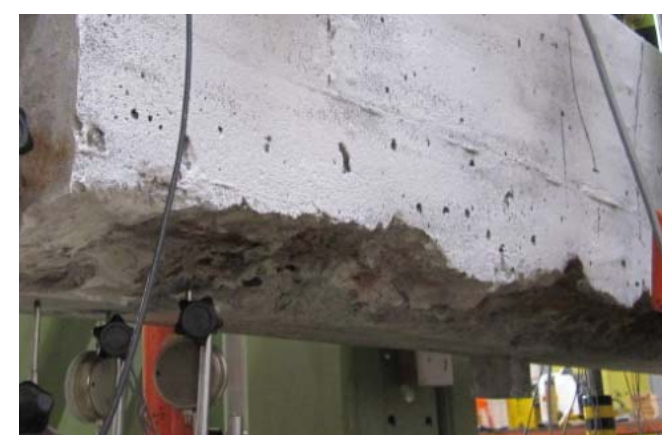

Figure 6. Photo taken before testing, at the end where failure later took place. Third test specimen, high corrosion with cover spalling.

\subsection{Results}

The second and third beam tests resulted in anchorage failure as wanted and had a good correspondence to the finite element analysis. This can be seen in Figure 7, where the average load of the two hydraulic jacks is plotted against the mid-span deflection, for both the two tests and the analysis. The maximum load in the specimen with low corrosion was about $270 \mathrm{kN}$, corresponding very well to the one resulting from the finite element analysis. In the 
test with a severely corroded specimen, the maximum load was almost as high: $255 \mathrm{kN}$. The threedimensional simulation showed a slightly stiffer behavior in the pre-peak stage. The experiments showed a considerable residual load-bearing capacity of about $70-75 \%$; this could not be followed in the analysis. The sudden drop in the post-peak stage, from the maximum load down to the more or less constant branch representing the residual capacity, indicates that the failure was not completely stable.

Figure 8 shows the average load versus the free end slip in the second test (with low corrosion). The corresponding result in the test with high corrosion degree is similar. As can be seen in Figure 8, all the main bars had a considerable slip of $0.1 \mathrm{~mm}$ in the pre-peak stage, which indicates that anchorage failure took place. Photos showing the crack patterns can be found in Figures 9 and 10 .

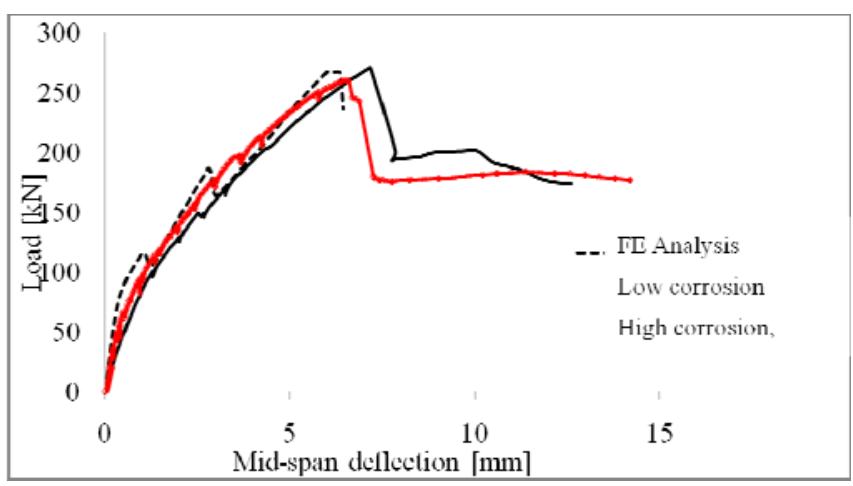

Figure 7. Results from second test: a) Average load versus mid span deflection, and b) Average load versus end slip.

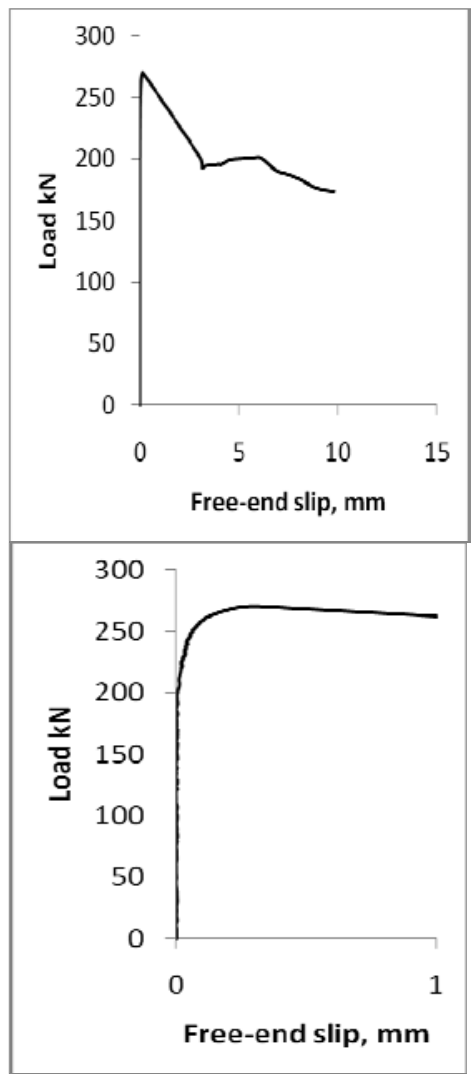

Figure 8. Average load versus end slip in second test, with low corrosion. b) is an enlargement of a).

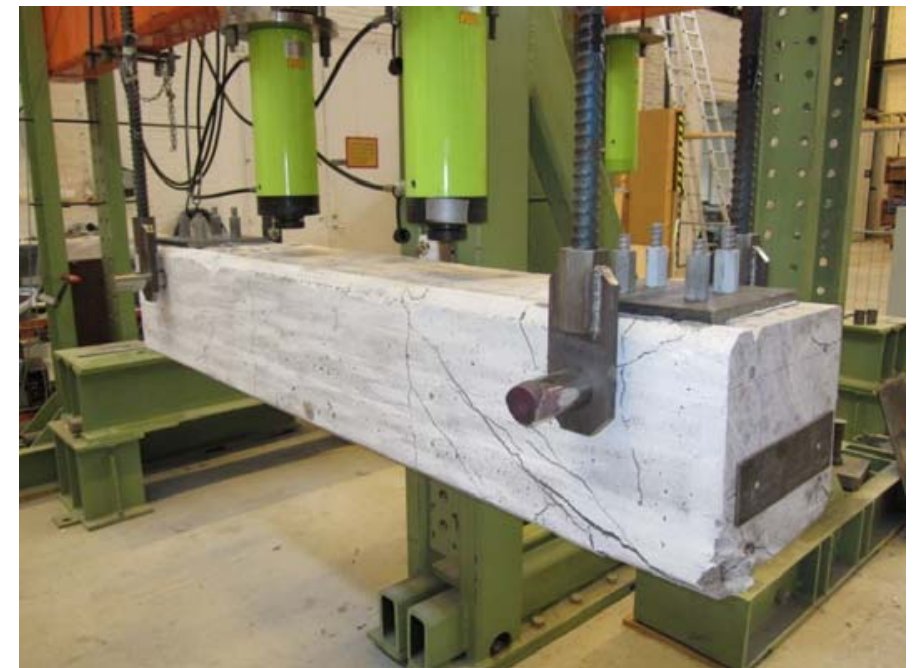

Figure 9. Second test specimen (low corrosion) after testing

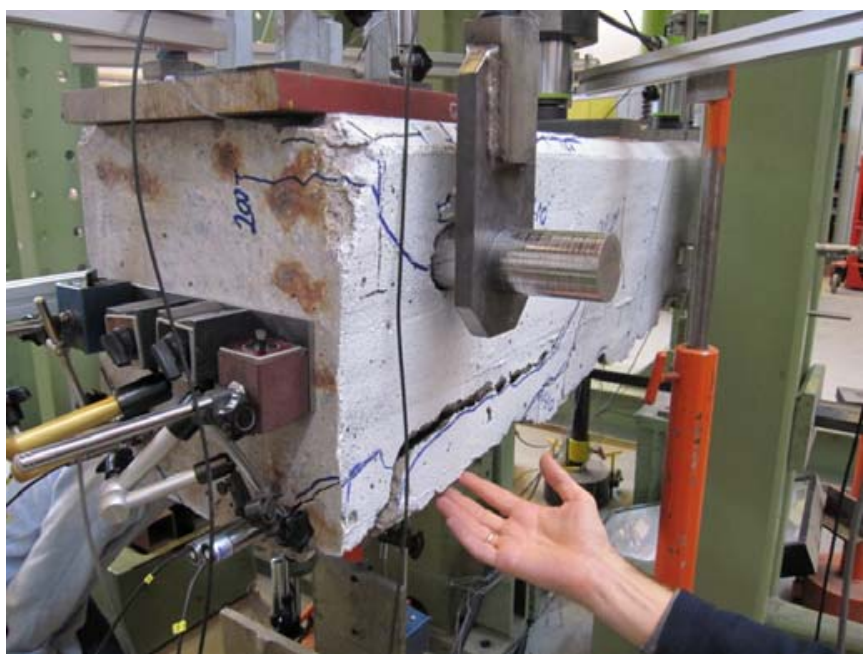

Figure 10. Third test specimen (high corrosion with cover spalling) at failure.

\section{CONCLUSIONS AND OUTLOOK}

A test set-up consisting of a four point bending test indirectly supported with suspension hangers was considered to be the best alternative with the least disturbance and influence of the natural damages. Detailed design was done by using a non-linear finite element method. It was seen that the edge beams needed to be strengthened with transverse reinforcement; else they would have failed in a local failure at the suspension hole or in shear. The technique adopted for the strengthening was an internal mounting of steel reinforcement using epoxy as adhesive. A first test showed that additional measures were needed to ensure anchorage of the strengthening bars. In subsequent tests, they were therefore anchored at the top of the beam with hexagonal nuts and flat steel plates. In two following tests, the beams failed in a splitting induced pull-out failure, i.e. anchorage failure was achieved as wanted. 
This work has opened for further experiments on edge beams from Stallbackabron. In a first series, test specimens are taken from the south part of the bridge; eight specimens in addition to the three described in this paper will be tested. A second series of tests are planned for with specimens from the north part of the bridge; these are planned to be tested in 2012. These tests will produce benchmark data of anchorage of naturally corroded reinforcement in bridges. They will be evaluated with detailed nonlinear finite element modeling, using the bond and corrosion model developed in Lundgren (2005b) and further developed in Zandi Hanjari et al. (2011).

\section{REFERENCES}

Austin S. A., Lyons R. and Ing M. J. 2004. Electrochemical behavior of steel-reinforced concrete during accelerated corrosion testing. Corrosion, Vol. 60, No. 2, pp. 203-212.

Berg F. and Johansson D. 2011. Design of test set-up using FEM: Pilot tests on anchorage of naturally corroded reinforcement. Master of Science Thesis, Civil and Environmental Engineering, Chalmers University of Technology, Gothenburg, 2011.

DIANA. 2009. DIANA Finite Element Analysis, User's Manual, release 9.3, TNO Building and Construction Research, Delft, Netherlands, 2009.

Swedish Standards Institute. 2002. Betongprovning med svensk standard. Stockholm, Sweden: SIS Förlag AB.

Lundgren K. 2001. Bond between Corroded Reinforcement and Concrete. Report number 00:3, Chalmers University of Technolgy, Gothenburg.

Lundgren K. 2005a. Bond between ribbed bars and concrete. Part 1: Modified model. Magazine of Concrete Research, Vol. 57, No. 7, pp. 371-382.

Lundgren K. 2005b. Bond between ribbed bars and concrete. Part 2: The effect of corrosion. Magazine of Concrete Research, Vol. 57, No. 7, pp. 383-395.

Lundgren K. and Magnusson J. 2001. Three-dimensional modelling of anchorage zones in reinforced concrete. ASCE Journal of Engineering Mechanics, Vol. 127, No. 7, July, pp. 693-699.

Magnusson J. 2000. Bond and Anchorage of Ribbed Bars in High-Strength Concrete. Ph.D. Thesis, Division of Concrete Structures, Chalmers University of Technology, Göteborg, 2000, pp. 299.

Saifullah M. and Clark L. A. 1994. Effect of corrosion rate on the bond strength of corroded reinforcement. Proceedings of International Conference: Corrosion and corrosion protection of steel in concrete, University of Sheffield, 1994, pp. 591-602.

Zandi Hanjari K. 2010. Structural Behaviour of Deteriorated Concrete Structures. Doctoral Thesis, Department of Civil and Environmental Engineering, Chalmers University of Technology, Gothenburg, 2010.

Zandi Hanjari K., Lundgren K., Plos M. and Coronelli D. 2011. Three-dimensional modelling structural effects of corroding steel reinforcement in concrete. Accepted for publication in Structure and Infrastructure Engineering. Published online 2011, http://dx.doi.org/10.1080/15732479.2011.607830. 